\title{
Prognostic value and association of Lauren classification with VEGF and VEGFR-2 expression in gastric cancer
}

\author{
XIAYI LI ${ }^{1}$, XUERU ZHU ${ }^{1}$, YIWEI WANG ${ }^{1}$, RUIFEN WANG $^{2}$, LIFENG WANG $^{2}$, \\ MEI-LING ZHU ${ }^{1}$ and LEIZHEN ZHENG ${ }^{1}$ \\ Departments of ${ }^{1}$ Oncology and ${ }^{2}$ Pathology, Xinhua Hospital, \\ School of Medicine, Shanghai Jiao Tong University, Shanghai 200092, P.R. China
}

Received February 27, 2019; Accepted August 15, 2019

DOI: $10.3892 / 01.2019 .10820$

\begin{abstract}
Gastric cancer (GC) is one of the most common malignant tumors in the world. As anti-angiogenic therapy shows efficacy in the treatment of GC, but only works in certain patients, the identification of potential beneficiaries are urgently required in order to apply appropriate treatments. The Lauren classification demonstrates numerous differences in etiology, epidemiology and pathology; however, the association between Lauren classification and pro-angiogenic factors remains unclear. The present study aimed to investigate the clinicopathological factors associated with Lauren classification and the prognostic significance of Lauren classification and vascular endothelial growth factor (VEGF) and VEGF receptor-2 (VEGFR-2) expression in GC. Paraffin-embedded GC tissues and clinical information of 255 patients with GC were collected. The clinicopathological factors associated with Lauren classification were evaluated by Logistic regression analysis. Kaplan-Meier survival and Cox regression analyses were used to examine the prognostic significance of Lauren classification and of VEGF and VEGFR-2 expression in patients with GC. The results demonstrated that there was no association between Lauren classification and VEGF and VEGFR-2 expression. Furthermore, results from survival analysis demonstrated that Lauren classification $(\mathrm{P}=0.001)$
\end{abstract}

Correspondence to: Dr Mei-Ling Zhu or Professor Leizhen Zheng, Department of Oncology, Xinhua Hospital, School of Medicine, Shanghai Jiao Tong University, 1665 Kong Jiang Road, Shanghai 200092, P.R. China

E-mail: zhumeiling@xinhuamed.com.cn

E-mail: zhengleizhen@xinhuamed.com.cn

Abbreviations: CI, confidence interval; GC, gastric cancer; HR, hazard ratio; OR, odd ratio; OS, overall survival; PFS, progression-free survival; TNM, tumor-node-metastasis; VEGF, vascular endothelial growth factor; VEGFR-2, vascular endothelial growth factor receptor-2

Key words: gastric cancer, Lauren classification, prognosis, vascular endothelial growth factor, vascular endothelial growth factor receptor-2 and Tumor-Node-Metastasis stage (stage II, $\mathrm{P}=0.002$; stage III, $\mathrm{P}<0.001$ ) were independent prognostic factors in GC. Following subgroup analysis based on Tumor-Node-Metastasis stage, Lauren classification was demonstrated to be an independent prognostic factor in patients with stage III GC $(\mathrm{P}=0.010)$ but not in patients with stage I or II GC. Furthermore, VEGFR-2 overexpression was an independent predictor of survival in intestinal-type GC ( $\mathrm{P}=0.040)$ but not in diffuse-type $\mathrm{GC}$. Taken together, these results indicate that Lauren classification may serve as an independent prognostic factor for patients with GC. In addition, although the expression of VEGF and VEGFR-2 was not associated with Lauren classification, VEGFR-2 overexpression may be considered as an independent prognostic factor in intestinal-type GC.

\section{Introduction}

Gastric cancer (GC) is one of the most common malignant tumors in the world, notably in China, where it has the highest incidence compared with other countries (1). In China, GC is the second most frequent type of cancer and the second leading cause of cancer-associated mortality. In 2015, GC accounted for 679,100 new cases and 498,000 mortalities (2). Despite the development of comprehensive treatment approaches, such as anti-HER2 therapy, immunotherapy and anti-angiogenetic therapy, the prognosis of GC remains poor and its current understanding remains limited.

Lauren classification has been widely accepted and used by pathologists and physicians since its introduction in 1965 (3). Lauren classification allows GC classification into three histological types, including intestinal-, diffuse- and mix-types, according to histopathological features of GC tissues (3). In intestinal-type GC, tumor cells exhibit adhesion and are arranged in tubular or glandular formations, whereas in diffuse-type GC, tumor cells infiltrate the stroma as single cells or small clusters due to lack of adhesion (3). Mix-type GC possesses all these characteristics (3). The proportion of men and elderly patients is higher in intestinal-type GC, whereas diffuse-type GC is more likely to happen in women and younger patients $(4,5)$. Lauren classification presents differences in etiology, epidemiology and pathology, which means that certain tumor development pathways are characteristics of different Lauren classifications $(4,6,7)$. 
Angiogenesis, a complex process involving multiple growth factors and signaling pathways, such as vascular endothelial growth factor (VEGF), angiopoietin, fibroblast growth factor and platelet-derived growth factor, is recognized as one of the 'hallmarks of cancer' and serves crucial role in tumor growth and progression (8). VEGF and its receptor VEGF receptor 2 (VEGFR-2) are the most important pro-angiogenic factors (9). Whether the angiogenic phenotype differs between the intestinal-type and diffuse-type of GC is controversial. Previous studies reported that intestinal-type GC is more dependent on angiogenesis than diffuse-type $(10,11)$; however, some studies reported opposite results and demonstrated that microvessel density was higher in diffuse-type GC compared with intestinal-type GC $(12,13)$.

Considering the poor prognosis of GC, it is crucial to determine prognostic factors for identifying high-risk patients and provide them with the appropriate treatment. The present study aimed to identify factors associated with Lauren classification and clarify whether VEGF and VEGFR-2 expression is associated with Lauren classification. Furthermore, the present study aimed to analyze the prognostic value of Lauren classification in patients with GC, and to investigate the prognostic value of VEGF and VEGFR-2 expression in different Lauren classifications.

\section{Materials and methods}

Patients. The present study was approved by the Ethics Committee of Xinhua Hospital, and written informed consent was obtained from all patients prior to the study. Data from 255 patients with GC who underwent surgical gastrectomy between July 2009 and July 2014 at the Xinhua Hospital, School of Medicine, Shanghai Jiao Tong University (Shanghai, China) were retrieved. The inclusion criteria were as follows: i) Gastric cancer was histologically confirmed; ii) adequate paraffin-embedded tumor tissue samples were provided for further analyses: and iii) complete medical records with regular follow-up data were accessible (the final follow-up time was August 2018 and the survival times were recorded). The exclusion criteria were as follows: i) Patients who suffered recurrences or multiple cancers; ii) patients who underwent preoperative chemotherapy or radiotherapy; and iii) patients with incomplete clinical information. The present study included the patients who received postoperative chemotherapy. A total of 255 patients with GC were included in the present study. The mean age at diagnosis was 63.8 years (range, 27-88 years) and the male-to-female ratio was 1.8:1.0.

Immunohistochemistry. Tumor tissues were obtained during surgery and fixed in $10 \%$ neutral buffered formalin for $24 \mathrm{~h}$ at room temperature. Tissues were then dehydrated with $70 \%$ ethanol for $40 \mathrm{~min}, 95 \%$ ethanol for $40 \mathrm{~min}, 95 \%$ ethanol for $40 \mathrm{~min}, 100 \%$ ethanol for $40 \mathrm{~min}$ and then $100 \%$ ethanol for $40 \mathrm{~min}$, all at room temperature. Tissues were incubated in xylene twice for $40 \mathrm{~min}$ at room temperature and then incubated in paraffin twice for $40 \mathrm{~min}$ at $60^{\circ} \mathrm{C}$. The tumor tissues were then embedded in paraffin to create a formalin-fixed, paraffin-embedded block and were stored at room temperature for the subsequent analyses.
Immunohistochemical analysis of VEGF and VEGFR-2 expression were conducted on paraffin-embedded tissue samples. Each paraffin-embedded sample was cut into $5 \mu \mathrm{m}$ slices and tissue slices were deparaffinized in xylene twice for $10 \mathrm{~min}$ at room temperature, rehydrated with $100 \%$ ethanol for $10 \mathrm{~min}, 100 \%$ ethanol for $10 \mathrm{~min}, 95 \%$ ethanol for $5 \mathrm{~min}$ and $75 \%$ ethanol for $5 \mathrm{~min}$, all at room temperature, and placed in $3 \% \mathrm{H}_{2} \mathrm{O}_{2}$ dissolved in methanol for $10 \mathrm{~min}$ at room temperature. Slices were then incubated with $10 \%$ normal goat serum (Beijing Solarbio Science \& Technology Co., Ltd.) for $60 \mathrm{~min}$ at room temperature. Following overnight incubation at $4^{\circ} \mathrm{C}$ with primary antibody against VEGF (cat. no. ab1316; 1:100; Abcam) and VEGFR-2 (cat. no. ab2349; 1:100; Abcam), slices were incubated for $30 \mathrm{~min}$ at room temperature with the horseradish peroxidase-conjugated secondary antibody Envision TM Detection kit (cat. no. GK500705; Sener Biotechnology) according to the manufacturer's instructions. Finally, all slices were incubated with diaminobenzidine (Beyotime Institute of Biotechnology) for 3-5 min at room temperature and counterstained with hematoxylin for $30 \mathrm{sec}$ at room temperature.

The slides were examined under light microscope (Olympus Corporation) at $\times 200$ magnification and the assessment of VEGF and VEGFR-2 staining was performed by two blinded pathologists as previously described (14). For VEGF expression, the staining intensity was scored as follows: i) 0 , no coloration; ii) 1 , light brown; iii) 2 , brown; and iv) 3 , dark brown. The percentage of stained cells was scored as 1, 2, 3, 4 or 5, for 0-20, 21-40, $41-60,61-80$ and $81-100 \%$ of positively stained cells, respectively. The total score was defined as follows: staining intensity score $\mathrm{x}$ percentage of positively stained cells. Total scores of 0-5 and $\geq 6$ were defined as VEGF (-) and VEGF (+), respectively. For VEGFR-2 expression, staining intensity was scored as follows: i) 0 , no coloration; ii) 1 , light brown; iii) 2 , brown; and iv) 3, dark brown. The percentage of stained cells was scored as $0,1,2,3$ and 4 for $0-5,6-25,26-50,51-75$ and $76-100 \%$ of positively stained cells, respectively. Total scores of 0-1, 2-4 and 5-12 were defined as VEGFR-2 (-), VEGFR-2 (+) and VEGFR-2 $(++-+++)$, respectively.

Lauren classification. Tumor tissue samples were examined by two experienced pathologists who were blinded to the patients' information and classified according to Lauren classification (3). The intestinal-type GC preserved the tubular or glandular appearance, whereas diffuse-type GC did not present tubular structures and comprised single or small clusters of cells. The mix-type GC was described as the combination of diffuse-type and intestinal-type.

Statistical analysis. SPSS 23.0 (IBM Corp.) and GraphPad Prism 7 (GraphPad Software, Inc.) software programs were used for all statistical analyses. A two-sided $\mathrm{P}<0.05$ was considered to indicate a statistically significant difference. Factors associated with diffuse-type GC were assessed using logistic regression analysis to calculate an odds ratio (OR) with a corresponding $95 \%$ confidence interval (CI). Overall survival (OS) time was calculated from the first day of surgery to the final day of follow-up (August 2018) or mortality. Univariate and multivariate Cox regression analyses were performed to calculate the hazards ratio (HR) and 95\% CI for identifying 
Table I. Clinicopathological features of 255 patients with gastric cancer.

\begin{tabular}{|c|c|c|}
\hline Variables & $\mathrm{n}$ & $\%$ \\
\hline \multicolumn{3}{|l|}{ Age, years } \\
\hline$\leq 65$ & 150 & 58.8 \\
\hline$>65$ & 105 & 41.2 \\
\hline \multicolumn{3}{|l|}{ Sex } \\
\hline Male & 164 & 64.3 \\
\hline Female & 91 & 35.7 \\
\hline \multicolumn{3}{|l|}{ TNM stage } \\
\hline $\mathrm{I}$ & 122 & 47.8 \\
\hline II & 51 & 20.0 \\
\hline III & 80 & 31.4 \\
\hline IV & 2 & 0.8 \\
\hline \multicolumn{3}{|l|}{ Differentiation } \\
\hline Moderate/well & 87 & 34.1 \\
\hline Poor & 168 & 65.9 \\
\hline \multicolumn{3}{|l|}{ Tumor location } \\
\hline Cardia & 18 & 7.1 \\
\hline Non-cardia & 237 & 92.9 \\
\hline \multicolumn{3}{|c|}{ Tumor diameter, $\mathrm{cm}$} \\
\hline$\leq 4$ & 180 & 70.6 \\
\hline$>4$ & 75 & 29.4 \\
\hline \multicolumn{3}{|l|}{ Smoking history } \\
\hline No & 187 & 73.3 \\
\hline Yes & 68 & 26.7 \\
\hline \multicolumn{3}{|l|}{ Drinking history } \\
\hline No & 225 & 88.2 \\
\hline Yes & 30 & 11.8 \\
\hline \multicolumn{3}{|l|}{ Family history } \\
\hline No & 238 & 93.3 \\
\hline Yes & 17 & 6.7 \\
\hline \multicolumn{3}{|l|}{ Chemotherapy } \\
\hline No & 154 & 60.4 \\
\hline Yes & 101 & 39.6 \\
\hline \multicolumn{3}{|c|}{ Lauren classification } \\
\hline Intestinal & 159 & 62.4 \\
\hline Diffuse & 91 & 35.7 \\
\hline Mix & 5 & 2.0 \\
\hline \multicolumn{3}{|c|}{ VEGF expression } \\
\hline$(-)$ & 210 & 82.4 \\
\hline$(+)$ & 45 & 17.6 \\
\hline \multicolumn{3}{|c|}{ VEGFR-2 expression } \\
\hline$(-)$ & 38 & 14.9 \\
\hline$(+)$ & 82 & 32.2 \\
\hline$(++-+++)$ & 135 & 52.9 \\
\hline
\end{tabular}

TNM, Tumor-Node-Metastasis; VEGF, vascular endothelial growth factor; VEFGR-2, VEGF receptor 2.

factors associated with GC prognosis. All variables in the univariate analysis were entered into the multivariate analysis to determine independent prognostic factors. Survival curves were calculated using Kaplan-Meier curve analysis, and a log-rank test was used to compare survival times within subgroups.

\section{Results}

Patient characteristics. The clinicopathological characteristics of the 255 patients with GC included in this study are presented in Table I. Almost half of the patients presented with stage I GC (47.8\%), and the majority of patients had poor differentiation $(65.9 \%)$, non-cardia location $(92.9 \%)$ and tumor diameter $\leq 4 \mathrm{~cm}(70.6 \%)$. Among the 255 patients with GC, $45(17.6 \%)$ cases presented VEGF (+), and $82(32.2 \%)$ and $135(52.9 \%)$ cases presented VEGFR $(+)$ and VEGFR $(++-+++)$, respectively. Representative pictures of VEGF and VEGFR-2 expression are presented in Fig. 1. There were 159 (62.4\%) patients with intestinal-type GC, 91 (35.7\%) patients with diffuse-type GC and 5 (2.0\%) patients with mix-type GC. Because only 2 patients presented with stage IV GC and 5 patients presented with mix-type GC, data from these patients were excluded. The data from 248 patients with GC were therefore used for further analysis.

Factors associated with Lauren classification. Univariate analysis demonstrated that stage III $(\mathrm{P}<0.001)$, poor differentiation $(\mathrm{P}<0.001)$, tumor diameter $>4 \mathrm{~cm}(\mathrm{P}=0.001)$, patients who received adjuvant chemotherapy $(\mathrm{P}<0.001)$ and VEGFR-2 $(+)(\mathrm{P}=0.048)$ were variables that were significantly associated with diffuse-type GC (Table II). Following multivariate analysis, poor differentiation (OR, 30.060; 95\% CI, 8.651-104.453; $\mathrm{P}<0.001)$, non-cardia location (OR, 4.681; 95\% CI, 1.025-21.376; $\mathrm{P}=0.046)$ and patients who received adjuvant chemotherapy (OR, 2.307; 95\% CI, 1.066-4.993; $\mathrm{P}=0.034)$ remained significantly associated with diffuse-type GC. The expression of VEGF and VEGFR-2 were not associated with Lauren classification following multivariate analysis (Table II).

Survival analysis for all patients. After a median follow-up period of 6.31 years, $168(67.7 \%)$ patients had survived and $80(32.3 \%)$ patients had died. Following univariate analysis, TNM stage (stage II, $\mathrm{P}<0.001$; stage III, $\mathrm{P}<0.001$ ), differentiation $(\mathrm{P}=0.017)$, tumor diameter $(\mathrm{P}<0.001)$, Lauren classification $(\mathrm{P}<0.001)$ and VEGFR-2 expression [VEGFR-2 $(+), \mathrm{P}=0.045$; VEGFR-2 $(++-+++), \mathrm{P}=0.004]$ were significantly associated with OS time (Table III). Following multivariate regression analysis, only TNM stage (stage II HR, 3.492; 95\% CI, 1.604-7.602; $\mathrm{P}=0.002$; stage III HR, 6.208; 95\% CI, 3.107-12.404; $\mathrm{P}<0.001)$ and Lauren classification ( $\mathrm{HR}, 2.660 ; 95 \% \mathrm{CI}, 1.512-4.680 ; \mathrm{P}=0.001)$ were significantly associated with patients OS time, and may therefore be considered as independent prognostic factors for OS time (Table III).

Survival analysis in subgroups. The association between Lauren classification and TNM stage for OS was evaluated using subgroup analyses. Kaplan-Meier curve and log-rank test demonstrated that Lauren classification was significantly associated with OS in stage III subgroup $(\mathrm{P}=0.001)$; however, 
A

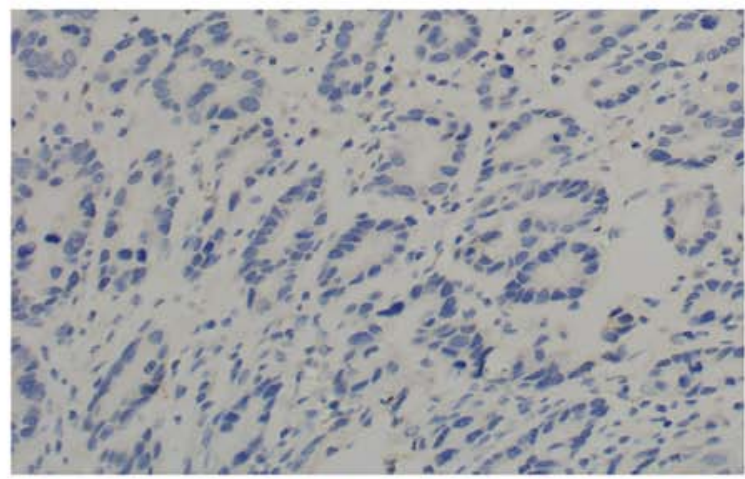

B

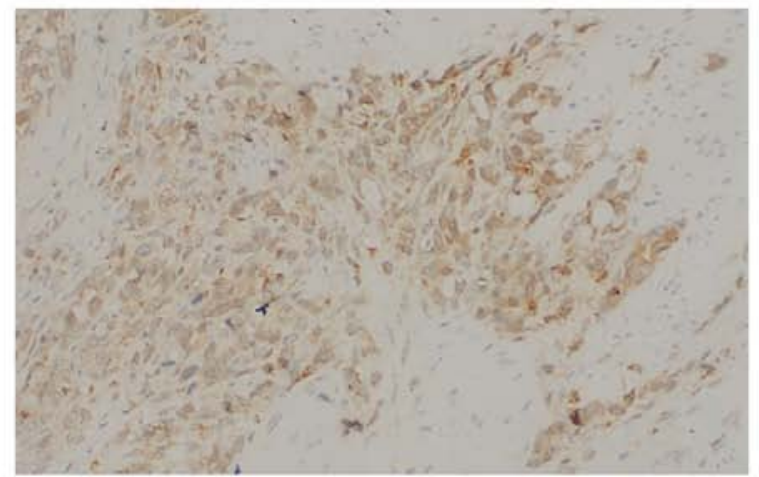

C

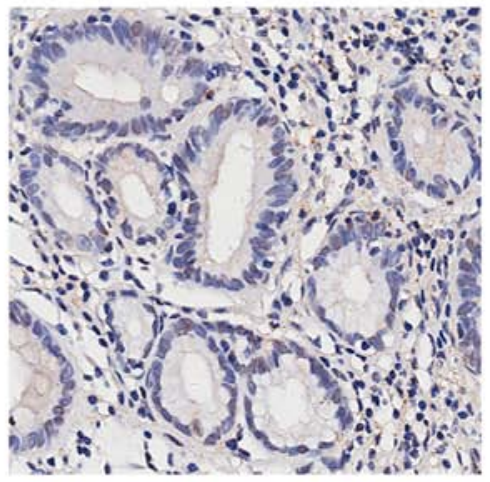

D

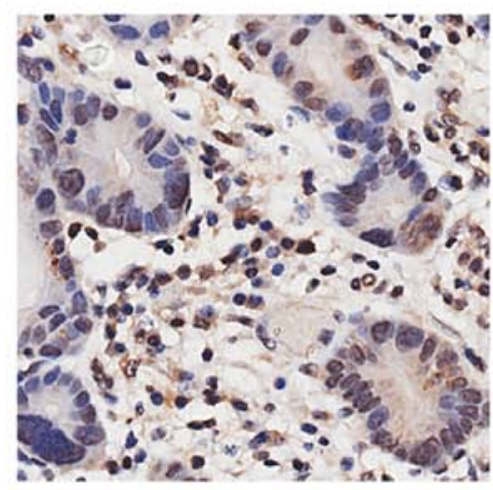

$E$

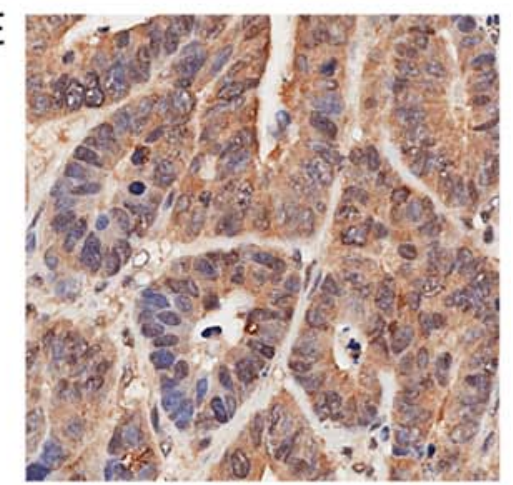

Figure 1. Immunohistochemical staining of VEGF and VEGFR-2 in gastric cancer tissues. (A) VEGF (-). (B) VEGF (+). (C) VEGFR-2 (-). (D) VEGFR-2 (+). (E) VEGFR-2 (++ - +++). Magnification, x200. VEGF, vascular endothelial growth factor; VEFGR-2, VEGF receptor 2.

this was not the case in stage $\mathrm{I}(\mathrm{P}=0.372)$ or stage $\mathrm{II}(\mathrm{P}=0.222)$ subgroups (Fig. 2). Furthermore, multivariate analysis demonstrated that Lauren classification was an independent prognostic factor in stage III subgroup (HR, 2.870; 95\% CI, 1.293-6.371; $\mathrm{P}=0.010$ ) (data not shown).

Based on the results of previous studies, VEGF/VEGFR-2 expression and Lauren classification are associated with clinical outcomes (15-17). Intestinal-type is more dependent on angiogenesis than diffuse-type (10), it is possible that the impact of VEGF and VEGFR-2 expression on clinical outcomes might differ between intestinal-type and diffuse-type GC. Therefore, we analyzed the impact of VEGF and VEGFR-2 expression on OS in different Lauren classifications. The results demonstrated a significant difference for VEGFR-2 expression only in the intestinal-type subgroup $(\mathrm{P}=0.001)$ (Fig. 3A). Subsequently, multivariate regression analysis in intestinal-type subgroup was performed, and demonstrated that VEGFR-2 (++ - +++) may be considered as an independent prognostic factor for OS (HR, 4.903; 95\% CI, 1.076-22.354; $\mathrm{P}=0.040$ ) (data not shown).

\section{Discussion}

Lauren classification can divide GC into intestinal-, diffuseand mix-types (18). Since mix-type GC possesses the characteristics of intestinal- and diffuse-types, only intestinaland diffuse-types GC were included in the present study. Previous studies investigating the clinicopathological characteristics of GC according to Lauren classification reported distinct clinical characteristics between the intestinal- and diffuse-types GC (4,19-21). It has been demonstrated that there are more patients $>65$ years and more male patients in intestinal-type GC compared with diffuse-type GC, and that intestinal-type GC is associated with less aggressive features, including smaller tumor size, well-differentiated tumors, less tumor invasion depth and less lymphovascular invasion (19). Conversely, diffuse-type GC is characterized by more aggressive features, including advanced pathological $\mathrm{T}$ and $\mathrm{N}$ stages and advanced TNM stage $(4,20)$.

In the present study, the proportion of diffuse-type GC was higher in patients with poor differentiation and non-cardia location, which was consistent with previous studies $(4,21)$. Furthermore, patients who had received adjuvant chemotherapy mostly suffered from diffuse-type GC, which could be explained by the higher proportion of patients with poor differentiation histological grade in this subgroup.

A more aggressive behavior of diffuse-type GC may contribute to the poor prognosis of patients with diffuse-type GC. Qiu et al (4) and Chen et al (19) demonstrated that the Lauren classification was an independent prognostic factor for survival time, which was consistent with the results of the present study. However, a number of studies have demonstrated that the Lauren classification represents a significant prognostic factor for survival following the univariate analysis, but was not identified as an independent predictor following the multivariate analysis $(22,23)$. This discrepancy may arise from different populations, limited sample size, various study design, among other things. Yamashita et al (22) suggested that diffuse-type advanced GC presenting with dismal prognosis was characterized by deeper invasion and emerging peritoneal cancer cell. The present study supports this suggestion, as it was also demonstrated that diffuse-type GC was a poor prognostic factor in stage III patients compared with stages I or II in the subgroup analysis. 
Table II. Factors associated with Lauren classification in patients with gastric cancer.

\begin{tabular}{|c|c|c|c|c|}
\hline \multirow[b]{2}{*}{ Variables } & \multicolumn{2}{|c|}{ Univariate analysis } & \multicolumn{2}{|c|}{ Multivariate analysis $^{\mathrm{a}}$} \\
\hline & OR $(95 \% \mathrm{CI})$ & $\mathrm{P}$-value & OR $(95 \% \mathrm{CI})$ & P-value \\
\hline \multicolumn{5}{|l|}{ Age, years } \\
\hline$\leq 65$ & 1.00 & & 1.00 & \\
\hline$>65$ & $0.807(0.474-1.375)$ & 0.430 & $0.941(0.451-1.963)$ & 0.872 \\
\hline \multicolumn{5}{|l|}{ Sex } \\
\hline Male & 1.00 & & 1.00 & \\
\hline Female & $1.203(0.702-2.062)$ & 0.502 & $1.125(0.542-2.334)$ & 0.752 \\
\hline \multicolumn{5}{|l|}{ TNM stage } \\
\hline I & 1.00 & & 1.00 & \\
\hline II & $1.142(0.553-2.358)$ & 0.720 & $0.637(0.247-1.639)$ & 0.349 \\
\hline III & $2.948(1.622-5.358)$ & $<0.001^{\mathrm{b}}$ & $1.274(0.531-3.058)$ & 0.587 \\
\hline \multicolumn{5}{|l|}{ Differentiation } \\
\hline Moderate/well & 1.00 & & 1.00 & \\
\hline Poor & $31.289(9.495-103.108)$ & $<0.001^{\mathrm{b}}$ & $30.060(8.651-104.453)$ & $<0.001^{\mathrm{b}}$ \\
\hline \multicolumn{5}{|l|}{ Tumor location } \\
\hline Cardia & 1.00 & & 1.00 & \\
\hline Non-cardia & $2.819(0.788-10.090)$ & 0.111 & $4.681(1.025-21.376)$ & $0.046^{\mathrm{a}}$ \\
\hline \multicolumn{5}{|c|}{ Tumor diameter, $\mathrm{cm}$} \\
\hline$\leq 4$ & 1.00 & & 1.00 & \\
\hline$>4$ & $2.525(1.428-4.466)$ & $0.001^{\mathrm{b}}$ & $1.646(0.740-3.660)$ & 0.221 \\
\hline \multicolumn{5}{|l|}{ Smoking history } \\
\hline No & 1.00 & & 1.00 & \\
\hline Yes & $1.038(0.577-1.867)$ & 0.902 & $0.977(0.413-2.31)$ & 0.958 \\
\hline \multicolumn{5}{|l|}{ Drinking history } \\
\hline No & 1.00 & & 1.00 & \\
\hline Yes & $1.276(0.580-2.809)$ & 0.545 & $2.639(0.742-9.390)$ & 0.134 \\
\hline \multicolumn{5}{|l|}{ Family history } \\
\hline No & 1.00 & & 1.00 & \\
\hline Yes & $0.519(0.164-1.642)$ & 0.264 & $0.557(0.127-2.431)$ & 0.436 \\
\hline \multicolumn{5}{|l|}{ Chemotherapy } \\
\hline No & 1.00 & & 1.00 & \\
\hline Yes & $2.659(1.558-4.537)$ & $<0.001^{\mathrm{b}}$ & $2.307(1.066-4.993)$ & $0.034^{\mathrm{b}}$ \\
\hline \multicolumn{5}{|l|}{ VEGF expression } \\
\hline$(-)$ & 1.00 & & 1.00 & \\
\hline$(+)$ & $0.819(0.408-1.647)$ & 0.576 & $0.619(0.248-1.545)$ & 0.304 \\
\hline \multicolumn{5}{|c|}{ VEGFR-2 expression } \\
\hline$(-)$ & 1.00 & & 1.00 & \\
\hline$(+)$ & $2.400(1.009-5.707)$ & $0.048^{\mathrm{b}}$ & $0.862(0.278-2.669)$ & 0.796 \\
\hline$(++-+++)$ & $1.808(0.788-4.147)$ & 0.162 & $0.631(0.208-1.909)$ & 0.415 \\
\hline
\end{tabular}

${ }^{a}$ Multivariate analysis was carried out by adjusting all parameters listed in Table II. ${ }^{b} \mathrm{P}<0.05$. CI, confidence interval; OR, odd ratio; TNM, Tumor-Node-Metastasis; VEGF, vascular endothelial growth factor; VEFGR-2, VEGF receptor 2.

Angiogenesis serves a crucial role in tumor cell survival and proliferation, and anti-angiogenic therapy has become a novel approach to treat cancer (24). Recently, numerous clinical studies on anti-angiogenic drugs have been performed in patients with GC (25-27). Ramucirumab, which is a human monoclonal antibody, can target the extracellular domain of VEGFR-2 and block the binding of VEGF, thereby preventing activation of the pro-angiogenic signaling pathway VEGF/VEGFR-2 (28). Furthermore, results from two randomized phase III trials (RAGARD and RAINBOW trials) allowed the US Food and Drug Administration (FDA) to approve ramucirumab monotherapy or combined with paclitaxel as 
Table III. Univariate and multivariate analyses of overall survival in all patients with gastric cancer.

\begin{tabular}{|c|c|c|c|c|}
\hline \multirow[b]{2}{*}{ Variables } & \multicolumn{2}{|c|}{ Univariate analysis } & \multicolumn{2}{|c|}{ Multivariate analysis ${ }^{\mathrm{a}}$} \\
\hline & HR $(95 \%$ CI $)$ & P-value & HR $(95 \% \mathrm{CI})$ & P-value \\
\hline \multicolumn{5}{|l|}{ Age, years } \\
\hline$\leq 65$ & 1.00 & & 1.00 & \\
\hline$>65$ & $1.264(0.813-1.967)$ & 0.298 & $1.095(0.613-1.955)$ & 0.759 \\
\hline \multicolumn{5}{|l|}{ Sex } \\
\hline Male & 1.00 & & 1.00 & \\
\hline Female & $1.096(0.695-1.729)$ & 0.694 & $0.988(0.581-1.642)$ & 0.928 \\
\hline \multicolumn{5}{|l|}{ TNM stage } \\
\hline $\mathrm{I}$ & 1.00 & & 1.00 & \\
\hline II & $3.545(1.762-7.129)$ & $<0.001^{\mathrm{a}}$ & $3.492(1.604-7.602)$ & $0.002^{\mathrm{b}}$ \\
\hline III & $7.606(4.186-13.820)$ & $<0.001^{\mathrm{a}}$ & $6.208(3.107-12.404)$ & $<0.001^{\mathrm{b}}$ \\
\hline \multicolumn{5}{|l|}{ Differentiation } \\
\hline Moderate/well & 1.00 & & 1.00 & \\
\hline Poor & $1.875(1.120-3.139)$ & $0.017^{\mathrm{a}}$ & $0.754(0.391-1.452)$ & 0.398 \\
\hline \multicolumn{5}{|l|}{ Tumor location } \\
\hline Cardia & 1.00 & & 1.00 & \\
\hline Non-cardia & $1.108(0.448-2.740)$ & 0.825 & $1.376(0.504-3.758)$ & 0.533 \\
\hline \multicolumn{5}{|c|}{ Tumor diameter, $\mathrm{cm}$} \\
\hline$\leq 4$ & 1.00 & & 1.00 & \\
\hline$>4$ & $3.158(2.035-4.901)$ & $<0.001^{\mathrm{b}}$ & $1.426(0.875-2.324)$ & 0.155 \\
\hline \multicolumn{5}{|l|}{ Smoking history } \\
\hline No & 1.00 & & 1.00 & \\
\hline Yes & $0.838(0.505-1.390)$ & 0.493 & $0.798(0.429-1.484)$ & 0.476 \\
\hline \multicolumn{5}{|l|}{ Drinking history } \\
\hline No & 1.00 & & 1.00 & \\
\hline Yes & $1.073(0.553-2.082)$ & 0.834 & $1.095(0.487-2.464)$ & 0.826 \\
\hline \multicolumn{5}{|l|}{ Family history } \\
\hline No & 1.00 & & 1.00 & \\
\hline Yes & $1.094(0.476-2.514)$ & 0.833 & $1.913(0.726-5.041)$ & 0.190 \\
\hline \multicolumn{5}{|l|}{ Chemotherapy } \\
\hline No & 1.00 & & 1.00 & \\
\hline Yes & $1.454(0.937-2.255)$ & 0.095 & $0.646(0.351-1.189)$ & 0.160 \\
\hline \multicolumn{5}{|c|}{ Lauren classification } \\
\hline Intestinal & 1.00 & & 1.00 & \\
\hline Diffuse & $2.716(1.747-4.222)$ & $<0.001^{\mathrm{b}}$ & $2.660(1.512-4.680)$ & $0.001^{\mathrm{b}}$ \\
\hline \multicolumn{5}{|l|}{ VEGF expression } \\
\hline$(-)$ & 1.00 & & 1.00 & \\
\hline$(+)$ & $0.616(0.318-1.196)$ & 0.152 & $0.933(0.454-1.920)$ & 0.852 \\
\hline \multicolumn{5}{|c|}{ VEGFR-2 expression } \\
\hline$(-)$ & 1.00 & & 1.00 & \\
\hline$(+)$ & $2.969(1.026-8.586)$ & $0.045^{\mathrm{b}}$ & $1.851(0.614-5.584)$ & 0.274 \\
\hline$(++-+++)$ & $4.529(1.639-12.517)$ & $0.004^{\mathrm{b}}$ & $2.292(0.795-6.610)$ & 0.125 \\
\hline
\end{tabular}

${ }^{a}$ Multivariate analysis was carried out by adjusting all parameters listed in Table II. ${ }^{b} \mathrm{P}<0.05$. CI, confidence interval; HR, hazard ratio; TNM, Tumor-Node-Metastasis; VEGF, vascular endothelial growth factor; VEFGR-2, VEGF receptor 2.

second-line treatment for patients with GC $(29,30)$. In addition, apatinib, which is a tyrosine kinase inhibitor that selectively inhibits VEGFR2, has been approved by the China FDA for patients with advanced GC (31). Furthermore, results from a 

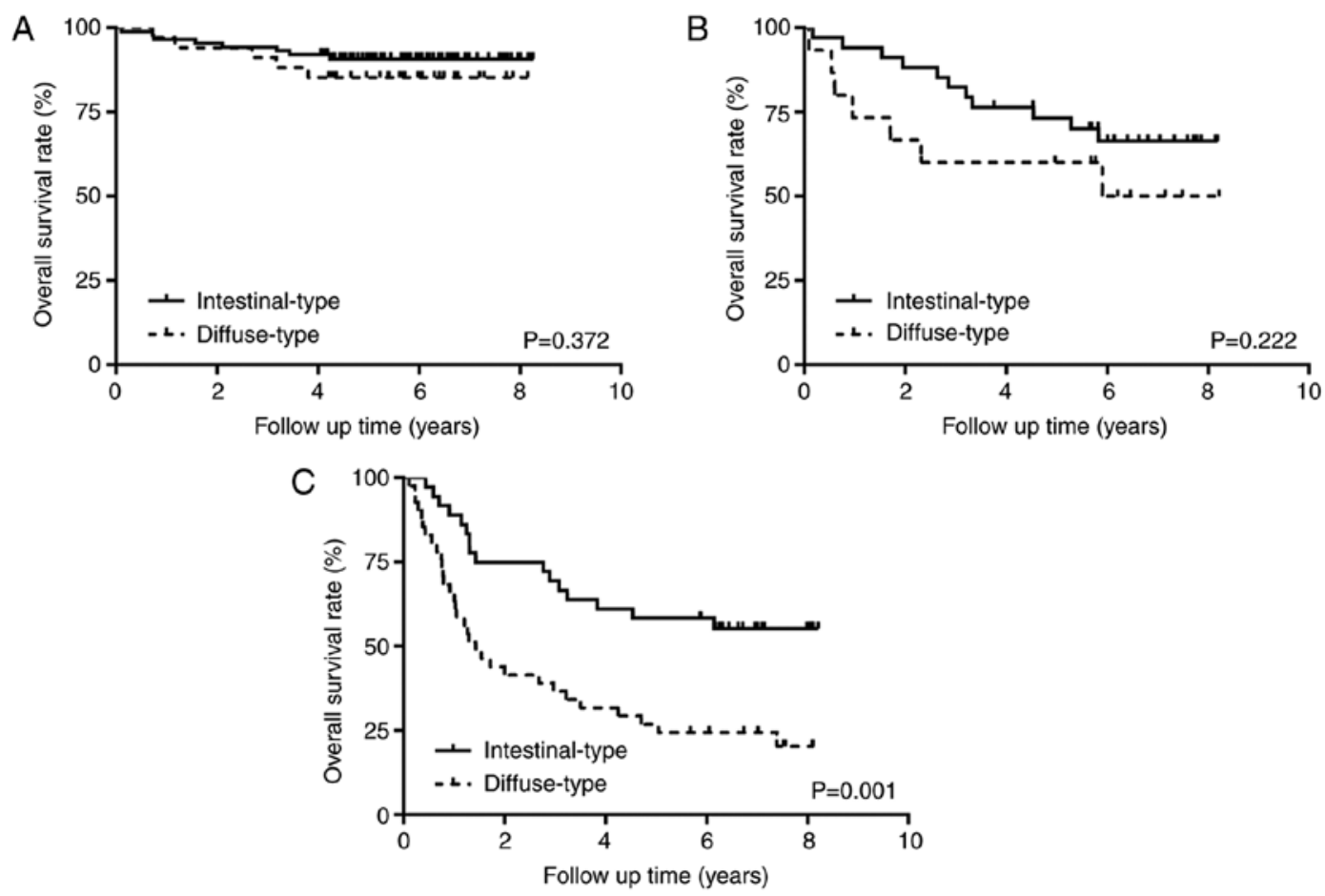

Figure 2. Kaplan-Meier survival analysis of the prognostic value of Lauren classification in patients with different Tumor-Node-Metastasis stages. (A) OS rate of patients with stage I GC according to Lauren classification. (B) OS rate of patients with stage II GC according to Lauren classification. (C) OS rate of patients with stage III GC according to Lauren classification. GC, gastric cancer; OS, overall survival.
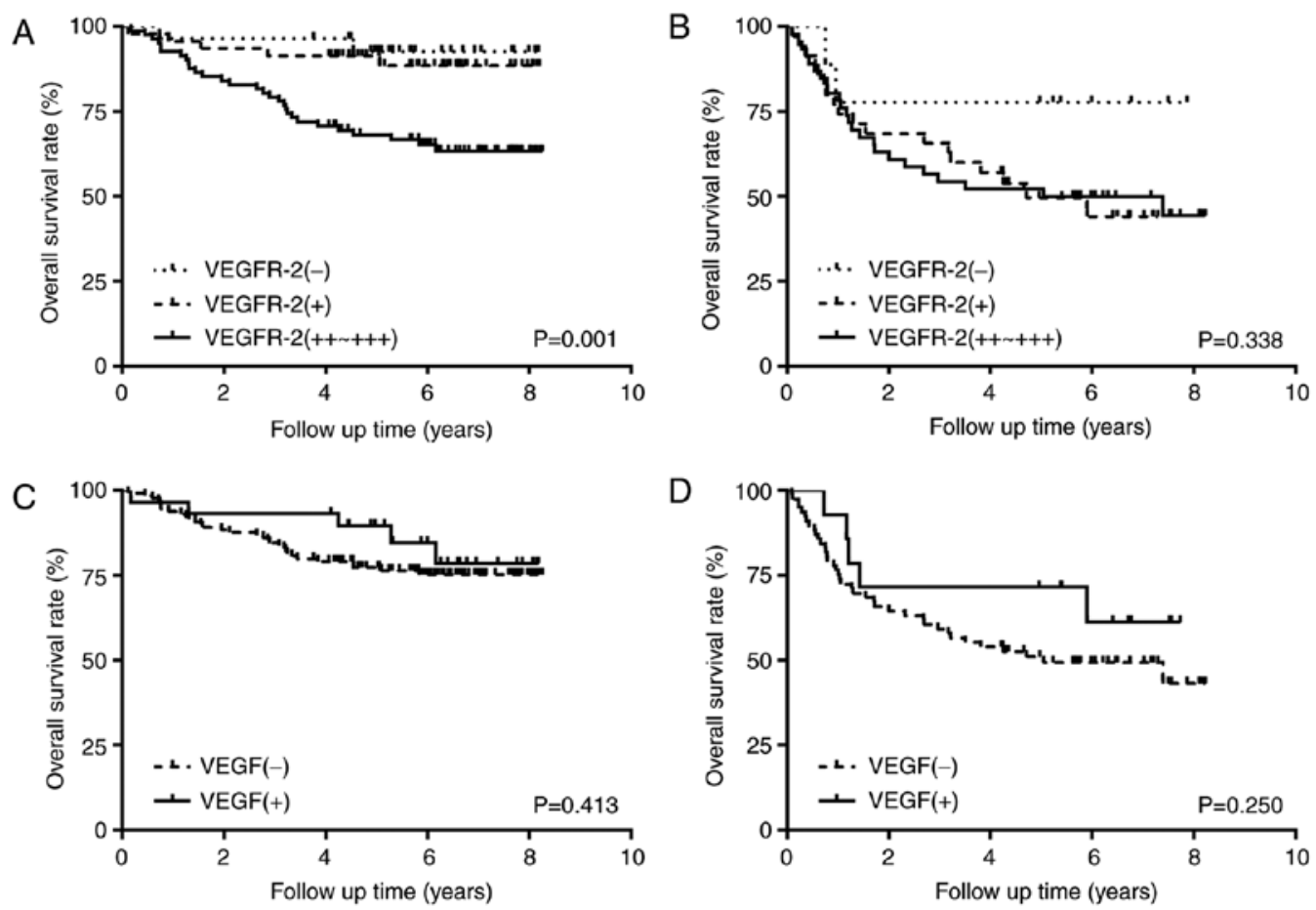

Figure 3. Kaplan-Meier survival analysis of the prognostic value of VEGF and VEGFR-2 expression in patients with GC according to Lauren classification. (A) OS rate of patients with intestinal-type GC according to VEGFR-2 expression. (B) OS rate of patients with diffuse-type GC according to VEGFR-2 expression. (C) OS rate of patients with intestinal-type GC according to VEGF expression. (D) OS rate of patients with diffuse-type GC according to VEGF expression. GC, gastric cancer; OS, overall survival; VEGF, vascular endothelial growth factor; VEFGR-2, VEGF receptor 2.

phase III trial demonstrated that apatinib treatment can significantly extend OS and progression-free survival (PFS) times in patients with GC who were refractory to at least two lines of chemotherapy (32). Bevacizumab is a recombinant humanized monoclonal antibody with high affinity for VEGF (33). A randomized, double-blind, phase III study demonstrated that bevacizumab combined with capecitabine-cisplatin as first-line treatment for GC can improve PFS but not OS in patients with 
GC; however, following subgroup analysis, bevacizumab was reported to prolong OS in the pan-America group (34).

As not many effective biomarkers for anti-angiogenic targeted therapy have been identified, their efficacy may be underestimated. Clarifying the association between Lauren classification and VEGF and VEGFR-2 expression, and performing subgroup survival analysis for VEGF/VEGFR-2 expression in different Lauren classifications may help with the identification of high-risk patients and provide them with the appropriate treatment.

It has been demonstrated that VEGF and VEGFR-2 are responsible for the formation of new blood vessels in intestinal-type GC (35). Similarly, Chen et al (36) indicated that VEGF expression in intestinal-type GC is significantly higher compared with in diffuse-type GC; however, other studies suggested that VEGF overexpression is significantly associated with diffuse-type GC $(37,38)$. The results from the present study demonstrated that VEGF and VEGFR-2 expression was not associated with Lauren classification, which was consistent with previous studies $(39,40)$. In addition, VEGF and VEGFR-2 expression were not associated with OS in all patients with GC. However, the results following subgroup survival analysis suggested that VEGFR-2 overexpression may be considered as an independent prognostic factor in intestinal-type GC. Whether patients with intestinal-type GC and VEGFR-2 overexpression could benefit from anti-angiogenic targeted therapy requires further investigation.

The present study exhibited some limitations. Firstly, it was a retrospective study and was conducted by a single-institution. Secondly, the sample size was relatively small and only patients with GC treated by surgical gastrectomy were included. Thirdly, $50 \%$ patients included in the study presented with stage I GC and the median OS was not reached. Large-scale and prospective multi-center studies are therefore required.

In conclusion, the results from the present study suggest that Lauren classification may be considered as an independent prognostic factor in patients with GC. Furthermore, Lauren classification exhibited prognostic significance for patients with stage III GC. The results also demonstrated that VEGF and VEGFR-2 expression was not associated with Lauren classification; however, results suggested that VEGFR-2 expression may be considered as an independent predictor of OS in patients with intestinal-type GC.

\section{Acknowledgements}

Not applicable.

\section{Funding}

This study was funded by the National Nature Science Foundation of China (grant no. 81602666), the Science and Technology Commission of Shanghai Municipality (grant no. 18DZ1910108), the Health and Family Planning Commission of Shanghai Municipality (grant no. 201540271) and Xin Hua Hospital Affiliated to Shanghai Jiao Tong University School of Medicine (grant no. 15LC05). The funders had no role in study design, data collection and analysis, or preparation of the manuscript.

\section{Availability of data and materials}

The datasets used and/or analyzed during the present study are available from the corresponding author upon reasonable request.

\section{Authors' contributions}

MZ and LZ designed the study and helped to draft and revise the manuscript. XL collected the follow-up data, performed the statistical analysis and wrote the manuscript. XZ and YW collected the clinical data and performed immunohistochemistry. RW and LW analyzed immunohistochemistry data and classified the gastric cancer cases. All authors read and approved the final manuscript.

\section{Ethics approval and consent to participate}

This study was approved by the Ethics Committee of Xinhua Hospital Affiliated to Shanghai Jiaotong University School of Medicine, Shanghai, China (approval no. XHEC-D-2015-152). Written informed consent was obtained from all patients prior to the study.

\section{Patient consent for publication}

Not applicable.

\section{Competing interests}

The authors declare that they have no competing interests.

\section{References}

1. Torre LA, Bray F, Siegel RL, Ferlay J, Lortet-Tieulent J and Jemal A: Global cancer statistics, 2012. CA Cancer J Clin 65: 87-108, 2015.

2. Chen W, Zheng R, Baade PD, Zhang S, Zeng H, Bray F, Jemal A, $\mathrm{Yu}$ XQ and He J: Cancer statistics in China, 2015. CA Cancer J Clin 66: 115-132, 2016.

3. Lauren P: The two histological main types of gastric carcinoma: Diffuse and so-called intestinal-type carcinoma. An attempt at a Histo-clinical classification. Acta Pathol Microbiol Scand 64: 31-49, 1965.

4. Qiu MZ, Cai MY, Zhang DS, Wang ZQ, Wang DS, Li YH and $\mathrm{Xu}$ RH: Clinicopathological characteristics and prognostic analysis of Lauren classification in gastric adenocarcinoma in China. J Transl Med 11: 58, 2013.

5. Gong EJ, Lee JY, Bae SE, Park YS, Choi KD, Song HJ, Lee GH, Jung HY, Jeong WJ, Cheon GJ, et al: Characteristics of non-cardia gastric cancer with a high serum anti-Helicobacter pylori IgG titer and its association with diffuse-type histology. PLoS One 13: e0195264, 2018.

6. Zheng H, Takahashi H, Murai Y, Cui Z, Nomoto K, Miwa S, Tsuneyama K and Takano Y: Pathobiological characteristics of intestinal and diffuse-type gastric carcinoma in Japan: An immunostaining study on the tissue microarray. J Clin Pathol 60: 273-277, 2007.

7. Min L, Zhao Y, Zhu S, Qiu X, Cheng R, Xing J, Shao L, Guo S and Zhang S: Integrated analysis identifies molecular signatures and specific prognostic factors for different gastric cancer subtypes. Transl Oncol 10: 99-107, 2017.

8. Hanahan D and Weinberg RA: Hallmarks of cancer: The next generation. Cell 144: 6466-6474, 2011.

9. Ferrara N, Gerber HP and LeCouter J: The biology of VEGF and its receptors. Nat Med 9: 669-676, 2003.

10. Kitadai Y: Angiogenesis and lymphangiogenesis of gastric cancer. J Oncol 2010: 468725, 2010.

11. Yamamoto S, Yasui W, Kitadai Y, Yokozaki H, Haruma K, Kajiyama G and Tahara E: Expression of vascular endothelial growth factor in human gastric carcinomas. Pathol Int 48: 499-506, 1998 
12. Bădescu A, Georgescu CV, Vere CC, Crăitoiu S and Grigore D Correlations between Her2 oncoprotein, VEGF expression, MVD and clinicopathological parameters in gastric cancer. Rom J Morphol Embryol 53: 997-1005, 2012.

13. Tenderenda M, Rutkowski P, Jesionek-Kupnicka D and Kubiak R: Expression of CD34 in gastric cancer and its correlation with histology, stage, proliferation activity, p53 expression and apoptotic index. Pathol Oncol Res 7: 129-134, 2001.

14. Zhu XR, Wang YW, Xue WJ, Wang R, Wang L, Zhu ML and Zheng L: The VEGFR-2 protein and the VEGFR-2 rs1870377 $\mathrm{A}>\mathrm{T}$ genetic polymorphism are prognostic factors for gastric cancer. Cancer Biol Ther 20: 497-504, 2019.

15. Lin C, Zhang Z, Xu Y, Wang R, Chen S, Gao J, Wang D, Huang Q, Tu X and Wang L: High tumor vascular endothelial growth factor expression is associated with poorer clinical outcomes in resected T3 gastric adenocarcinoma. Am J Clin Pathol 146: 278-288, 2016.

16. Li T, Yu J, Luo X, Ren W, Zhang Y and Cao B: VEGFR-2 as a novel predictor of survival in gastric cancer: A systematic review and meta-analysis. Pathol Res Pract 214: 560-564, 2018

17. Polkowski W, van Sandick JW, Offerhaus GJ, ten Kate FJ, Mulder J, Obertop H and van Lanschot JJ: Prognostic value of Laurén classification and c-erbB-2 oncogene overexpression in adenocarcinoma of the esophagus and gastroesophageal junction. Ann Surg Oncol 6: 290-297, 1999.

18. Berlth F, Bollschweiler E, Drebber U, Hoelscher AH and Moenig S: Pathohistological classification systems in gastric cancer: Diagnostic relevance and prognostic value. World J Gastroenterol 20: 5679-5684, 2014.

19. Chen YC, Fang WL, Wang RF, Liu CA, Yang MH, Lo SS Wu CW, Li AF, Shyr YM and Huang KH: Clinicopathological variation of Lauren classification in gastric cancer. Pathol Oncol Res 22: 197-202, 2016.

20. Stiekema J, Cats A, Kuijpers A, van Coevorden F, Boot H, Jansen EP, Verheij M, Balague Ponz O, Hauptmann M and van Sandick JW: Surgical treatment results of intestinal and diffuse type gastric cancer. Implications for a differentiated therapeutic approach? Eur J Surg Oncol 39: 686-693, 2013.

21. Qiu M, Zhou Y, Zhang X, Wang Z, Wang F, Shao J, Lu J, Jin Y, Wei X, Zhang D, et al: Lauren classification combined with HER2 status is a better prognostic factor in Chinese gastric cancer patients. BMC Cancer 14: 823, 2014.

22. Yamashita K, Sakuramoto S, Katada N, Futawatari N, Moriya H, Hirai K, Kikuchi S and Watanabe M: Diffuse type advanced gastric cancer showing dismal prognosis is characterized by deeper invasion and emerging peritoneal cancer cell: The latest comparative study to intestinal advanced gastric cancer. Hepatogastroenterology 56: 276-281, 2009.

23. Yu CC, Levison DA, Dunn JA, Ward LC, Demonakou M, Allum WH and Hallisey MT: Pathological prognostic factors in the second British Stomach Cancer Group trial of adjuvant therapy in resectable gastric cancer. Br J Cancer 71: 1106-1110, 1995.

24. Rajabi M and Mousa SA: The role of angiogenesis in cancer treatment. Biomedicines 5: pii: E34, 2017.

25. Cleary JM, Horick NK, McCleary NJ, Abrams TA, Yurgelun MB, Azzoli CG, Rubinson DA, Brooks GA, Chan JA, Blaszkowsky LS, et al: FOLFOX plus ziv-aflibercept or placebo in first-line metastatic esophagogastric adenocarcinoma: A double-blind, randomized, multicenter phase 2 trial. Cancer: Mar 26, 2019 (Epub ahead of print). doi: 10.1002/cncr.32029.

26. Kim ST, Lee J, Lee SJ, Park SH, Jung SH, Park YS, Lim HY Kang WK and Park JO: Prospective phase II trial of pazopanib plus CapeOX (capecitabine and oxaliplatin) in previously untreated patients with advanced gastric cancer. Oncotarget 7 : 24088-24096, 2016

27. Fuchs CS, Shitara K, Di Bartolomeo M, Lonardi S, Al-Batran SE, Van Cutsem E, Ilson DH, Alsina M, Chau I, Lacy J, et al: Ramucirumab with cisplatin and fluoropyrimidine as first-line therapy in patients with metastatic gastric or junctional adenocarcinoma (RAINFALL): A double-blind, randomised, placebo-controlled, phase 3 trial. Lancet Oncol 20: 420-435, 2019
28. Fontanella C, Ongaro E, Bolzonello S, Guardascione M, Fasola G and Aprile G: Clinical advances in the development of novel VEGFR2 inhibitors. Ann Transl Med 2: 123, 2014.

29. Fuchs CS, Tomasek J, Yong CJ, Dumitru F, Passalacqua R, Goswami C, Safran H, Dos Santos LV, Aprile G, Ferry DR, et al: Ramucirumab monotherapy for previously treated advanced gastric or gastro-oesophageal junction adenocarcinoma (REGARD): An international, randomised, multicentre, placebo-controlled, phase 3 trial. Lancet 383: 31-39, 2014.

30. Wilke H, Muro K, Van Cutsem E, Oh SC, Bodoky G, Shimada Y, Hironaka S, Sugimoto N, Lipatov O, Kim TY, et al: Ramucirumab plus paclitaxel versus placebo plus paclitaxel in patients with previously treated advanced gastric or gastro-oesophageal junction adenocarcinoma (RAINBOW): A double-blind, randomised phase 3 trial. Lancet Oncol 15: 1224-1235, 2014.

31. Aoyama T and Yoshikawa T: Targeted therapy: Apatinib-new third-line option for refractory gastric or GEJ cancer. Nat Rev Clin Oncol 13: 268-270, 2016.

32. Li J, Qin SK, Xu JM, Xiong J, Wu C, Bai Y, Liu W, Tong J, Liu Y, $\mathrm{Xu}$ R, et al: Randomized, double-blind, placebo-controlled phase III trial of apatinib in patients with chemotherapy-refractory advanced or metastatic adenocarcinoma of the stomach or gastroesophageal junction. J Clin Oncol 34: 1448-1454, 2016.

33. Roviello G, Petrioli R, Marano L, Polom K, Marrelli D, Perrella A and Roviello F: Angiogenesis inhibitors in gastric and gastroesophageal junction cancer. Gastric Cancer 19: 31-41, 2016.

34. Ohtsu A, Shah MA, Van Cutsem E, Rha SY, Sawaki A, Park SR, Lim HY, Yamada Y, Wu J, Langer B, et al: Bevacizumab in combination with chemotherapy as first-line therapy in advanced gastric cancer: A randomized, double-blind, placebo-controlled phase III study. J Clin Oncol 29: 3968-3976, 2011.

35. Takahashi Y, Cleary KR, Mai M, Kitadai Y, Bucana CD and Ellis LM: Significance of vessel count and vascular endothelial growth factor and its receptor (KDR) in intestinal-type gastric cancer. Clin Cancer Res 2: 1679-1684, 1996.

36. Chen CN, Hsieh FJ, Cheng YM, Cheng WF, Su YN, Chang KJ and Lee PH: The significance of placenta growth factor in angiogenesis and clinical outcome of human gastric cancer. Cancer Lett 213: 73-82, 2004.

37. Wang L, Yang M, Shan L, Qi L, Chai C, Zhou Q, Yao K, Wu H and Sun W: The role of SPARC protein expression in the progress of gastric cancer. Pathol Oncol Res 18: 697-702, 2012.

38. Wang X, Cao W, Mo M, Wang W, Wu H and Wang J: VEGF and cortactin expression are independent predictors of tumor recurrence following curative resection of gastric cancer. J Surg Oncol 102: 325-330, 2010

39. Lastraioli E, Boni L, Romoli MR, Crescioli S, Taddei A, Beghelli S, Tomezzoli A, Vindigni C, Saragoni L, Messerini L, et al: VEGF-A clinical significance in gastric cancers: Immunohistochemical analysis of a wide Italian cohort. Eur J Surg Oncol 40: 1291-1298, 2014.

40. Chen L, Shi Y, Yuan J, Han Y, Qin R, Wu Q, Jia B, Wei B, Wei L, Dai G and Jiao S: HIF-1 alpha overexpression correlates with poor overall survival and disease-free survival in gastric cancer patients post-gastrectomy. PLoS One 9: e90678, 2014.

This work is licensed under a Creative Commons Attribution-NonCommercial-NoDerivatives 4.0 International (CC BY-NC-ND 4.0) License. 